\title{
Multi-Walled CNT Reinforcement to Thermal Spray Coatings
}

\author{
Rakesh Goyal $^{1}$, Buta Singh Sidhu ${ }^{2}$ and Vikas Chawla ${ }^{3}$ \\ ${ }^{1}$ Chitkara University Institute of Engineering \& Technology, Chitkara University, India \\ ${ }^{2}$ Dean (P\&D), MRS Punjab Technical University, Bathinda, Punjab, India \\ ${ }^{3}$ Department of Mechanical Engineering, IKG Punjab Technical University, Kapurthala, Punjab, India \\ E-Mail: butasidhu@yahoo.com
}

\begin{abstract}
Thermal spraying coating techniques have emerged as very effective surface protection technology to apply protective coatings for corrosion and wear resistance applications. These coatings have gained more importance in recent past. Advances in powder and wire production have resulted in development of various types of surface coatings with excellent wear and corrosion resistance properties. Because of excellent mechanical, thermal and electrical properties of Carbon Nanotubes, CNTs reinforced composite coatings are being developed for various applications, e.g. automotive, aerospace and sports equipment industry. It is observed that if properly deposited, these CNTs ceramic composite coatings can provide improved properties like wear and corrosion resistance. It has been found that CNTs composite coatings can be successfully deposited by thermal spraying techniques, and these coatings provide better performance than conventional coatings. This paper reviews the performance of such coatings developed by various researchers.
\end{abstract}

Keywords: Hot Corrosion, Thermal Spraying, Carbon Nanotubes, Properties, Reinforcements

\section{INTRODUCTION}

The material conservation has become an important concern due to ever increasing global competition [1]. Corrosion is defined as the deterioration of materials by reaction with the environment. Corrosion affects properties that are to be preserved. This mode of degradation of metals at high temperature is known as oxidation or dry corrosion. At elevated temperature, the surfaces of metals and alloys are covered with thin film of fused salt, known as hot corrosion [2]. Advancements in development of materials and cooling technologies have led to increase in operating temperature of gas turbines, boilers and industrial waste incinerators [3]. The use of low grade fuels along with high temperature requires special attention to the phenomenon of hot corrosion [4-6].

The problem of hot corrosion was taken as serious problem first time with the degradation of boiler tubes in steam generating plants and degradation of gas turbine air-foil materials in 1940's [7-9]. Hot corrosion consumes material at an unpredictably rapid rate which reduces the load carrying ability of the component and this leads to the catastrophic failure of the component [2]. Due to failure of components, the plants face closure and reduction in efficiency. Billions of dollars are spent every year for the replenishment of corroded parts, machines and equipment
[10]. The sudden failure of components can lead to human injury and loss of life. It is estimated that the direct cost due to hot corrosion in United States is 3-5\% of the Gross Domestic Product [11].

Due to low price and worldwide availability, coal is being used as fuel in power plants. The combustion of coal generates corrosive agents particularly in high temperature zone of the boiler [12]. The $\mathrm{Na}, \mathrm{V}, \mathrm{K}$ and $\mathrm{S}$ are present in fuel as impurities. These impurities form low melting point compounds and get deposited on the surface of material and subsequently induce corrosion [13, 14]. These impurities reach with each other to form $\mathrm{Na}_{2} \mathrm{SO}_{4}, \mathrm{~V}_{2} \mathrm{O}_{5}$ and other complex vanadates. These molten deposits destroy the naturally formed protective oxide layers on the materials during boiler operation [15]. Sodium vanadyl vanadate $\left(\mathrm{Na}_{2} \mathrm{O} . \mathrm{V}_{2} \mathrm{O}_{4} .5 \mathrm{~V}_{2} \mathrm{O}_{5}\right)$ is common salt deposit on boiler tubes and it melts at low temperature of $550{ }^{\circ} \mathrm{C}$ [16]. Vandate deposits are good oxidation catalysts and these compounds allow oxygen and other gasses in high temperature atmosphere to diffuse rapidly into the metal substrate and accelerate corrosion. In coal gasification processes, hot corrosion is severe problem because the operating environment contains low oxygen and large sulphur along with substantial amount of salts [17].

Hot corrosion is of two types i.e. High temperature hot corrosion and Low temperature hot corrosion. The high temperature hot corrosion is observed within temperature range of $850-950{ }^{\circ} \mathrm{C}[5,18]$. It starts with deposition of alkali metal salts on surface of components. Subsequent chemical reactions deplete the protective oxide film and attack chromium element in the substrate material. The depletion of chromium leads to oxidation of base material, formation of porous scale and peeling of metal [19]. Low temperature hot corrosion is observed within temperature range of $650-800{ }^{\circ} \mathrm{C}$. The low melting point mixture of $\mathrm{Na}_{2} \mathrm{SO}_{4}$ and $\mathrm{CoSO}_{4}$ cause pitting in the localized areas [19, 20]. The erosion-corrosion is the phenomenon occurred due to the combined action of flow of hot flue gases and corrosion. The erosion-corrosion leads to the accelerated rate of loss of materials from boiler tubes and this is a serious problem in boilers. Therefore, the combination of contaminants, high operating temperatures, low grade fuels and high velocity of impacting fly ash require special attention in boilers [21, 22]. It is very important to study such degradations of metals and allows to prevent the loss 
of metals to ascertain safety and reliability of components [23].

\section{THERMAL SPRAY COATINGS}

No material is resistant to hot corrosion attack for a long time. In the past, superalloys have been developed and used in high temperature applications to reduce the corrosion, but many times these superalloys are not able to resist high temperature corrosion [2]. Therefore, coatings have been developed to provide protection against hot corrosion [24]. Due to increase in the requirements of materials as well as rising cost of materials, these coatings technologies have gained importance in recent past. Although these coatings are costly but these can add 10 times value than the cost of coating by increasing life time of materials. The coating compositions are determined by the type of application and material requirements [25]. The coatings allow mechanical properties of the substrate materials to be maintained while protecting the substrate material against corrosion and erosion [13]. The coatings provide a barrier amongst the coated substrate and the environment and thus increasing the corrosion resistance [26].

Thermal spray coatings have been used extensively for both performance and life enhancement of the boiler components [27]. Thermal spray process has important characteristics such as flexibility in coating material selection, low substrate thermal input and almost no substrate dissolution [28].

Plasma spraying is versatile and well established technique to apply coatings for improved corrosion resistance on boiler components [29]. Plasma spray technique has advantage of depositing ceramics, metals and a combination of these and generates homogenous coatings with desired microstructure on a vide rage of substrate materials [30]. Plasma sprayed coatings of various ceramic materials such as Alumina $\left(\mathrm{Al}_{2} \mathrm{O}_{3}\right)$, Calcia $(\mathrm{Ca})$-stabilized zirconia $\left(\mathrm{ZrO}_{2}\right)$ and other refractory materials have been developed for various high temperature applications [12, 27, 30-33]. Alumina is an exceptionally important ceramic material which has many technological applications. It has high hardness, chemical inertness and high melting point. It can retain up to $90 \%$ of its strength even at $1100{ }^{\circ} \mathrm{C}$ [34]. It is reported that the corrosion resistance of alumina coatings are higher than that of cermets and metallic coatings [35]. There is an increasing demand on these coatings with increased thermal characteristics [36]. It is not possible to produce defect free plasma spray coatings. The thermal spray coatings consist of cracks or voids. These voids originate from the spraying process and are detected at the splat boundaries. In the corrosive environment, these coatings are attacked through these voids [37-39]. Therefore, despite success of thermal spray coatings in recent past, there has still a great interest among researchers to develop new coating materials for enhanced corrosion resistance at high temperature [40].

\section{CARBON NANOTUBES AS REINFORCEMENT MATERIALS}

With the invention of Carbon nanotubes (CNTs) in 1991, a new era of interest in the field of nanotechnology began [ 41 , 42]. Iijima discovered microtubules of graphite carbon which are arranged in the form of a cylinder known as carbon nanotubes [43]. Carbon nanotubes possess exceptionally enhanced mechanical, thermal and electrical properties as compared to carbon steels [44, 45]. Carbon nanotubes are 100's of times stronger than the high grade carbon steels and have many times higher tensile modulus than steel [46-48]. These properties of CNTs make them potential reinforcement for the composite materials [40]. A few researchers have used CNTs-Metal composite coatings to enhance the corrosion resistance of $\mathrm{Ni}$ and $\mathrm{Zn}$ based composite coatings $[49,50]$. CNTs acted as inert physical barriers to the origination and development of corrosion, altering the microstructure of the nickel layer and hence improving the corrosion resistance of the coating. It is revealed in the literature that very few investigations have been made on the corrosion behavior of CNTs-metal composite coatings. Some researchers have developed different wt. $\%$ CNTs- $\mathrm{Al}_{2} \mathrm{O}_{3}$ composite coatings and studied the tribological behavior [51-55].

\section{COMPREHENSIVE RESEARCH CARRIED ON CNT REINFORCED COATINGS}

Kaewsai, et al. [56] developed stainless steel-carbon nanotube composite coatings by thermal spraying from the feedstock powder synthesized by chemical vapour deposition at a synthesis temperature and time of $800{ }^{\circ} \mathrm{C}$ and 120 minutes under ethanol atmosphere. It was observed that developed CNTs covering the surface of stainless steel particles were multi-walled type with an average diameter of about $44 \mathrm{~nm}$ and had splat characteristic and lamellar structure. The CNTs were clearly observed in the composite coating. The hardness of composite coating was higher than that of pure steel coating, whereas the coefficient of friction was almost 3 times lower than that of stainless steel coating. It was concluded that CNT reinforced coatings gave improved wear resistive performance in comparison to stainless steel coatings.

Singhal, et al. [57] have fabricated Al-matrix composites reinforced with amino-functionalized multiwalled carbon nanotubes (fCNTs) using the powder metallurgy process. fCNTs (1.5 wt. \%) were mixed in $\mathrm{Al}$ powder by ball milling process (high). Al-fCNTs composites $(1.5 \mathrm{wt} . \%)$ were made up by the integration of powders at $550 \mathrm{MPa}$ and then sintered at $620^{\circ} \mathrm{C}$ under a vacuum of $10^{-2}$ Torr for 2 hours. It was noticed that the dispersion of fCNTs in Al-matrix was much higher than those of non-functionalized MWCNTs. Microhardness was observed to be $400 \mathrm{~kg} / \mathrm{mm} 2$ for Al-matrix composites loaded with $1.5 \mathrm{wt} \%$ fCNTs. It was found that the sintered composites had a good dispersion of fCNTs in $\mathrm{Al}$ matrix and they did not agglomerate with each other. It was concluded that the 
formation of a thin transition layer of $\mathrm{Al}_{4} \mathrm{C}_{3}$ between fCNTs and $\mathrm{Al}$ matrix was responsible for load transfer from $\mathrm{Al}$ matrix to fCNTs.

Al-CNT composites with different quantities of CNTs were made up to inquire the effect of the dispersion of carbon nanotubes in the ceramic matrix on the tribological behaviour [58]. The composites with CNT content up to 12 wt. $\%$ were made up by tape casting and then by lamination and hot pressing. The wear behaviour of the CNT reinforced composites was inquired by using a ball-on-reciprocating wear tester under an un-lubricated condition at room temperature. It was observed that the wear rate of hotpressed samples diminishes with increasing up to $4 \mathrm{wt} . \%$, but the wear rate increased again with the further addition of CNT. The wear rate of the tape casted composites reduced uniformly with increasing CNT addition up to $12 \mathrm{wt} . \%$.

Kwok, et al. [59] Deposited CNT reinforced HA coatings on Ti6Al4V followed by vacuum sintering at $800{ }^{\circ} \mathrm{C}$. Submicron HA powders with spherical, needle-shaped and flake-shaped morphologies were used in the EDP process to develop dense coatings. Electrochemical corrosion behavior of the HA coatings in Hanks' solution was inquired by means of open-circuit potential measurement and cyclic potentiodynamic polarization tests. Surface hardness, adhesion strength and bone bioactivity of the coatings were also studied. It was found that the HA coated specimens had a thickness of about $10 \mathrm{~mm}$ with corrosion resistance higher than that of the substrate and adhesion strength higher than that of plasma sprayed coating. It was found that the CNTreinforced HA coating markedly increased the coating hardness without compromising the corrosion resistance or adhesion strength.

Tribological behavior of plasma sprayed carbon nanotube reinforced aluminum oxide $\left(\mathrm{Al}_{2} \mathrm{O}_{3}\right)$ composite coatings was investigated at room temperature, $573 \mathrm{~K}$ and $873 \mathrm{~K}$ using tungsten carbide by Keshri, et al. [51]. It was found that the weight loss due to wear of $\mathrm{Al}_{2} \mathrm{O}_{3}$ coating was increasing with the temperature while $\mathrm{Al}_{2} \mathrm{O}_{3}$-CNT coating showed a decreasing weight loss with the temperature. Increase in wear resistance of $\mathrm{Al}_{2} \mathrm{O}_{3}$-CNT coating compared to $\mathrm{Al}_{2} \mathrm{O}_{3}$ coating was $12 \%$ at room temperature which gradually increased to $56 \%$ at $573 \mathrm{~K}$ and $82 \%$ at $873 \mathrm{~K}$. It was concluded that the improvement in the wear resistance of $\mathrm{Al}_{2} \mathrm{O}_{3}$-CNT coating was due to higher hardness at the elevated temperature as compared to $\mathrm{Al}_{2} \mathrm{O}_{3}$ coating, and CNTs bridging between splats. The coefficient of friction of $\mathrm{Al}_{2} \mathrm{O}_{3}$ coating was nearly constant at room and $873 \mathrm{~K}$ whereas that for $\mathrm{Al}_{2} \mathrm{O}_{3}-\mathrm{CNT}$ coating decreased at $873 \mathrm{~K}$.

Keshri, et al. [51] investigated the effect of carbon nanotube (CNT) addition on the splat formation in plasma sprayed aluminum oxide $\left(\mathrm{Al}_{2} \mathrm{O}_{3}\right)$ composite coating with 0,4 and 8 wt.\% CNTs in $\mathrm{Al}_{2} \mathrm{O}_{3}$ matrix. It was observed that with an increasing CNT content, splat morphology became more circular and disk-shaped. The average diameter of diskshaped splats increased with increase in CNT content. The addition of CNTs increased thermal capacity and increased viscosity of the melt. Increase in thermal capacity delayed the localized solidification which resulted in higher splat diameter while agglomeration of CNTs at the periphery of the splat resulted in higher viscosity of the melt which suppressed the splat fragmentation.

Mazaheri, et al. [60] developed multi-walled carbon nanotube nanostructured zirconia composites with a homogenous distribution of different MWCNT quantities (ranging within 0.5-5 wt.\%). An increase in indentation fracture toughness and a slight hardness improvement were observed with the addition of 5 wt.\% (12.5 vol.\%) MWCNTs. This was attributed to the extent of interfacial bonding between MWCNTs and zirconia grains. High temperature mechanical tests of zirconia/MWCNTs nanostructured composites showed a significant reduction of plastic strain in the presence of MWCNTs while monolithic zirconia exhibited superplastic deformation.

Ahmad, et al. [52] fabricated multi-walled carbon nanotubes (CNTs) reinforced $\mathrm{Al} 2 \mathrm{O} 3$ nanocomposites hot-pressing resulted in improvements in fracture toughness, by $94 \%$ and $65 \%$ with 2 and 5 wt.\% CNTs addition respectively, compared with monolithic $\mathrm{Al}_{2} \mathrm{O}_{3}$. The increase in mechanical properties was attributed to the good dispersion of CNTs within the matrix, crack-bridging by CNTs and strong interfacial connections between the CNTs and the matrix. It was observed that a possible aluminium oxycarbide interfacial phase was produced via a localized carbo thermal reduction process which had good chemical compatibility and strong connections with both CNTs.

Keshri, et al. [61] used chemical vapour deposition method to achieve a homogeneous dispersion of carbon nanotubes (CNTs) on aluminum oxide $\left(\mathrm{Al}_{2} \mathrm{O}_{3}\right)$ powder deposited by plasma spray method on a steel substrate to produce a $96 \%$ dense $\mathrm{Al}_{2} \mathrm{O}_{3}$ coating with $\mathrm{CNT}$ reinforcement. It was observed that with the addition of $1.5 \mathrm{wt} . \%$ CNTs there was $24 \%$ increase in the relative fracture toughness of the composite coating. The improvement was due to uniform dispersion of CNTs and toughening mechanism such as CNT bridging, crack deflection and strong interaction between $\mathrm{CNT} / \mathrm{Al}_{2} \mathrm{O}_{3}$ interfaces. The wear tests were performed by ball on disk tribometer. It was observed that with increase in normal loads from 10 to $50 \mathrm{~N}$, the wear volume loss and coefficient of friction of the coating was increased. It was also found that wear resistance of the $\mathrm{Al}_{2} \mathrm{O}_{3}-\mathrm{CNT}$ composite coating improved by $27 \%$ at $50 \mathrm{~N}$.

Li, et al. [62] developed Zirconia/graphene nanosheets $\left(\mathrm{ZrO}_{2} / \mathrm{GNs}\right)$ composite coatings using a plasma spraying technique. It was observed that the graphene nanosheets additives $(1 \mathrm{wt} \%)$ were homogeneously distributed in the $\mathrm{ZrO}_{2}$ matrix and most of them were anchored at the splat interface. The results of wear test showed that the $\mathrm{ZrO}_{2}$ /graphene nanosheets composite coating exhibited good wear resistance and low friction with the addition of graphene nanosheets. The wear rate of composite coating 
was reduced to $1.17 \times 10^{-6} \mathrm{~mm}^{3} / \mathrm{N} \mathrm{m}$ at $100 \mathrm{~N}$, which corresponded to a $50 \%$ decrease compared with the pure $\mathrm{ZrO}_{2}$ coating.

A dispersion process for producing carbon nanotube (CNT)reinforced magnesium alloy (CNT/AZ31) composites was developed by Han, et al. [63]. The process included the preparation of a $\mathrm{CNT} / \mathrm{fMg}$ precursor with uniformly dispersed CNTs followed by the synthesis of CNT/AZ31 composites by subsequent melting and hot extrusion. It was observed that the CNTs uniformly dispersed in the molten AZ31 without agglomeration because of the use of the $\mathrm{CNT} / \mathrm{Mg}$ precursor. The structure of the CNTs was remained intact and was not destroyed, and good interfacial bonding existed between the CNTs and the AZ31 matrix. The tensile yield strength of the CNT composite was $22.7 \%$ greater than that of AZ31 alloy. It was due to the heterogeneous nucleation effect of the CNTs and the good interfacial bonding between the CNTs and the matrix.

Bakshi, et al. [64] developed multiwalled carbon nanotube (CNT) reinforced aluminum nanocomposite coatings using cold gas kinetic spraying. A good dispersion of the nanotubes in micron-sized gas atomized $\mathrm{Al}-\mathrm{Si}$ eutectic powders was obtained by using spray drying. 5 wt.\% CNT were blended with pure aluminum powder to give overall nominal CNT compositions of $0.5 \mathrm{wt} \%$ and 1 wt. $\%$ respectively. It was observed that the cold spraying resulted in coatings of the order of $500 \mu \mathrm{m}$ in thickness. CNTs were found to be shortened in length due to fracture that occurred due to impact and shearing between $\mathrm{Al}-\mathrm{Si}$ eutectic particles and the aluminum matrix. It was found that the elastic modulus values were from 40-229 GPa which was attributed to microstructural heterogeneity of the coatings that comprised pure $\mathrm{Al}, \mathrm{Al}-\mathrm{Si}$ eutectic, porosity and CNTs.

\section{EXPERIMENTAL RESEARCH ON CNT REINFORCED COATINGS}

The authors have also developed multiwalled carbon nanotube $(\mathrm{CNT})$ reinforced $\mathrm{Al}_{2} \mathrm{O}_{3}$ coatings using Plasma spraying. A good dispersion of the nanotubes in alumina powder was obtained by using low energy ball milling method. Alumina powder was blended to give overall nominal CNT compositions of 1.5 wt. $\%, 2$ wt.\% and 4 wt. $\%$ respectively. It was observed that the Plasma spraying resulted in coatings of the order of $225 \mu \mathrm{m}$ average thickness. Further the reinforcement of CNTs has resulted in an decrease in porosity, improvement in adhesive strength of the coating. The boiler tube steel substrates coated with these compositions were tested for cyclic oxidation in air and molten salt environment and in actual industrial boiler environment at $900{ }^{\circ} \mathrm{C}$ temperature. The primary results of this experimental study disclosed that $\mathrm{CNT}-\mathrm{Al}_{2} \mathrm{O}_{3}$ composite coatings are more corrosion resistant as compared to $\mathrm{Al}_{2} \mathrm{O}_{3}$ coating. The outcomes of corrosion weight gain for all the three environments were agreeing to each other. Furthermore, it has been observed from the experimentation that coating with higher CNT composition has been the most beneficial for boiler steels in all the environments.

\section{CONCLUSION}

1. Studies showed that carbon nanotubes reinforced composite coatings are very useful to improve the material properties when synthesized using various thermal spray techniques

2. Carbon nanotubes were dispersed uniformly between splat boundaries and retention of CNTs in the composite matrix was observed, where CNTs were intact without any damaged between these boundaries and within the core of composite

3. CNTs reinforced coatings possessed better mechanical properties viz. high elastic modulus, high hardness, good wear properties than conventional coatings

4. Because of uniform dispersion the CNTs reinforced is useful to decrease porosity and to increase teh adhesion strength in comparison to conventional coatings.

5. The CNT reinforcement in alumina coatings have been found effective in providing better corrosion resistance in all the environments

6. Much of the CNTs reinforcement was studied for thermally sprayed ceramic coatings for Aluminum based matrix and hydroxyapatite structure, whereas limited research publication observed in other matrix composites. There is large scope to investigate the wear and corrosion behaviour of CNTs reinforced in different metal matrix thermally sprayed composite coatings.

\section{REFERENCES}

[1] J. Lawrence and L. Li, "Surface treatment of an Al 2 O 3-based refractory with $\mathrm{CO} 2$ and high power diode lasers for improved mechanical and chemical resistance characteristics," Surface and Coatings Technology, Vol. 162, No. 1, pp. 93-100, 2003.

[2] T. Sidhu, S. Prakash, and R. Agrawal, "Hot corrosion and performance of nickel-based coatings," Current science, No. 90 , 2006.

[3] H. Singh, T. Sidhu, J. Karthikeyan, and S. Kalsi, "Evaluation of characteristics and behavior of cold sprayed $\mathrm{Ni}-20 \mathrm{Cr}$ coating at elevated temperature in waste incinerator plant," Surface and Coatings Technology, Vol. 261, pp. 375-384, 2015.

[4] R. Jones, "Hot Corrosion in Gas Turbines," DTIC Document1983.

[5] N. Eliaz, G. Shemesh, and R. Latanision, "Hot corrosion in gas turbine components," Engineering Failure Analysis, Vol. 9, No. 1, pp. 31-43, 2002.

[6] A. López, M. Proy, V. Utrilla, E. Otero, and J. Rams, "Hightemperature corrosion behavior of $\mathrm{Ni}-50 \mathrm{Cr}$ coating deposited by high velocity oxygen-fuel technique on low alloy ferritic steel," Materials \& Design, Vol. 59, pp. 94-102, 2014.

[7] R. A. Rapp, "Hot corrosion of materials: a fluxing mechanism?," Corrosion science, Vol. 44, No. 2, pp. 209-221, 2002.

[8] M. Kaur, H. Singh, and S. Prakash, "High-Temperature Corrosion Studies of HVOF-Sprayed Cr3C2-NiCr Coating on SAE-347H Boiler Steel," Journal of thermal spray technology, Vol. 18, No. 4, pp. 619632, 2009.

[9] R. Kumar, V. Tewari, and S. Prakash, "Studies on hot corrosion of the $2.25 \mathrm{Cr}$-1Mo boiler tube steel and its weldments in the molten salt Na2SO4-60 pet V2O5 environment," Metallurgical and Materials Transactions A, Vol. 38, No. 1, pp. 54-57, 2007.

[10] B. S. Sidhu and S. Prakash, "Evaluation of the behavior of shrouded plasma spray coatings in the platen superheater of coal-fired boilers," 
metallurgical and Materials Transactions A, Vol. 37, No. 6, pp. 1927-1936, 2006.

[11] A. Vardelle and S. Kuroda, "Coatings under severe conditions," Journal of Thermal Spray Technology, Vol. 16, No. 1, pp. 1-2, 2007.

[12] B. S. Sidhu and S. Prakash, "Studies on the behaviour of stellite-6 as plasma sprayed and laser remelted coatings in molten salt environment at $900 \mathrm{C}$ under cyclic conditions," Journal of materials processing technology, Vol. 172, No. 1, pp. 52-63, 2006.

[13] S. S. Chatha, H. S. Sidhu, and B. S. Sidhu, "Characterisation and corrosion-erosion behaviour of carbide based thermal spray coatings," Journal of Minerals and Materials Characterization and Engineering, Vol. 11, No. 06, p. 569, 2012.

[14] A. Wong-Moreno and D. López-López, "Erosion, corrosion and deposits in gas turbines burning heavy, high sulphur fuel oil," Corrosion Reviews, Vol. 14, No. 3-4, pp. 265-296, 1996.

[15] H. Singh, D. Puri, and S. Prakash, "An overview of Na 2 SO 4 and/or V 2 O 5 induced hot corrosion of Fe-and Ni-based superalloys," Rev. Adv. Mater. Sci, Vol. 16, No. 1-2, pp. 27-50, 2007.

[16] M. M. Barbooti, S. H. Al-Madfai, and H. J. Nassouri, "Thermochemical studies on hot ash corrosion of stainless steel 304 and inhibition by magnesium sulphate," Thermochimica acta, Vol. 126, pp. 43-49, 1988.

[17] K. Natesan, "Corrosion-erosion behavior of materials in a coalgasification environment," Corrosion, Vol. 32, No. 9, pp. 364-370, 1976.

[18] B. Gleeson, "High-Temperature Corrosion of Metallic Alloys and Coatings," Materials science and technology, 2000.

[19] R. A. Rapp, "Chemistry and electrochemistry of the hot corrosion of metals," corrosion, Vol. 42, No. 10, pp. 568-577, 1986.

[20] G. Meier, "A review of advances in high-temperature corrosion," Materials Science and Engineering: A, Vol. 120, pp. 1-11, 1989.

[21] B. Wang, "Erosion-corrosion of thermal sprayed coatings in FBC boilers," Wear, Vol. 199, No. 1, pp. 24-32, 1996.

[22] V. Chawla, "Microstructural Characteristics and Mechanical Properties of Nanostructured and Conventional TiAlN and AlCrN Coatings on ASTM-SA210 Grade A-1 Boiler Steel," ISRN Corrosion, Vol. 2013, p. 14, 2013

[23] T. Sidhu, S. Prakash, and R. Agrawal, "Studies of the metallurgical and mechanical properties of high velocity oxy-fuel sprayed stellite-6 coatings on Ni-and Fe-based superalloys," Surface and Coatings Technology, Vol. 201, No. 1-2, pp. 273-281, 2006.

[24] B. Singh, A. Jain, and V. Chawla, "Evaluation of erosion-corrosion resistance of some detonation gun sprayed coatings on grade A-1 boiler steel in a coal fired boiler," IOSRD International Journal of Engineering, Vol. 2, No. 1, pp. 13-18, 2015.

[25] R. Unger, "Thermal spray coatings," ASM International, ASM Handbook., Vol. 13, pp. 459-462, 1987.

[26] N. Bala, H. Singh, and S. Prakash, "High Temperature Corrosion Behavior of Cold Spray Ni-20Cr Coating on Boiler Steel in Molten Salt Environment at $900 \mathrm{C}$," Journal of thermal spray technology, Vol. 19, No. 1-2, pp. 110-118, 2010.

[27] K. Katiki, S. Yadlapati, and S. N. S. Chidepudi, "Comparative High Temperature Corrosion Studies on Zirconium Dioxide Coated Inconel 625 in Air and Molten Salt Environment," International Journal of ChemTech Research, Vol. 6, No. 11, pp. 4579-45845, 2014.

[28] U. Schulz, C. Leyens, K. Fritscher, M. Peters, B. Saruhan-Brings, O. Lavigne, et al., "Some recent trends in research and technology of advanced thermal barrier coatings," Aerospace science and technology, Vol. 7, No. 1, pp. 73-80, 2003.

[29] L. Erickson, R. Westergård, U. Wiklund, N. Axen, H. Hawthorne, and S. Hogmark, "Cohesion in plasma-sprayed coatings-a comparison between evaluation methods," Wear, Vol. 214, No. 1, pp. 30-37, 1998

[30] B. S. Sidhu, D. Puri, and S. Prakash, "Mechanical and metallurgical properties of plasma sprayed and laser remelted $\mathrm{Ni}-20 \mathrm{Cr}$ and Stellite6 coatings," Journal of Materials Processing Technology, Vol. 159, No. 3, pp. 347-355, 2005.

[31] J. KARTHIKEYAN, K. Sreekumar, N. VENKATRAMANI, and V. Rohatgi, "Preparation and characterization of plasma-sprayed thick ceramic coatings reinforced with metal pins," High Temperatures. High Pressures, Vol. 20, No. 6, pp. 653-660, 1988.

[32] A. N. Khan and J. Lu, "Thermal cyclic behavior of air plasma sprayed thermal barrier coatings sprayed on stainless steel substrates," Surface and Coatings Technology, Vol. 201, No. 8, pp. 4653-4658, 2007.
[33] L. Du, W. Zhang, W. Liu, and J. Zhang, "Preparation and characterization of plasma sprayed Ni 3 Al-hBN composite coating," Surface and Coatings Technology, Vol. 205, No. 7, pp. 2419-2424, 2010

[34] N. Hegazy, M. Shoeib, S. Abdel-Samea, and H. Abdel-Kader, "'Effect of plasma sprayed alumina coating on corrosion resistance'," in Proc. 13th Int. Conf. on 'Aerospace sciences and aviation technology', Cairo, Egypt, 2009, pp. 1-10.

[35] E. Celik, I. Ozdemir, E. Avci, and Y. Tsunekawa, "Corrosion behaviour of plasma sprayed coatings," surface and coatings technology, Vol. 193, No. 1, pp. 297-302, 2005.

[36] P. Ananthapadmanabhan, K. Sreekumar, K. Muraleedharan, and N. Venkatramani, "Plasma-sprayed composite coatings for high temperature applications," Surface and Coatings Technology, Vol. 49, No. 1, pp. 62-66, 1991.

[37] S. Deshpande, A. Kulkarni, S. Sampath, and H. Herman, "Application of image analysis for characterization of porosity in thermal spray coatings and correlation with small angle neutron scattering," Surface and coatings technology, Vol. 187, No. 1, pp. 616, 2004.

[38] S. Deshpande, S. Sampath, and H. Zhang, "Mechanisms of oxidation and its role in microstructural evolution of metallic thermal spray coatings - Case study for Ni-Al," Surface and Coatings Technology, Vol. 200, No. 18, pp. 5395-5406, 2006.

[39] S. Kamal, R. Jayaganthan, and S. Prakash, "Evaluation of cyclic hot corrosion behaviour of detonation gun sprayed $\mathrm{Cr} 3 \mathrm{C} 2-25 \% \mathrm{NiCr}$ coatings on nickel-and iron-based superalloys," Surface and coatings technology, Vol. 203, No. 8, pp. 1004-1013, 2009.

[40] M. K. Singla, H. Singh, and V. Chawla, "Thermal Sprayed CNT Reinforced Nanocomposite Coatings-A Review," J. Miner. Mater. Charact. Eng, Vol. 10, No. 8, pp. 717-726, 2011.

[41] J. Andzelm, N. Govind, and A. Maiti, "Nanotube-based gas sensorsRole of structural defects," Chemical Physics Letters, Vol. 421, No. 1, pp. 58-62, 2006.

[42] B. Yu and M. Meyyappan, "Nanotechnology: role in emerging nanoelectronics," Solid-state electronics, Vol. 50, No. 4, pp. 536-544, 2006.

[43] S. Iijima, "Helical microtubules of graphitic carbon," nature, Vol. 354, No. 6348, pp. 56-58, 1991.

[44] Z. Han and A. Fina, "Thermal conductivity of carbon nanotubes and their polymer nanocomposites: a review," Progress in polymer science, Vol. 36, No. 7, pp. 914-944, 2011.

[45] K. Liew, X. He, and C. Wong, "On the study of elastic and plastic properties of multi-walled carbon nanotubes under axial tension using molecular dynamics simulation," Acta Materialia, Vol. 52, No. 9, pp. 2521-2527, 2004.

[46] M.-F. Yu, O. Lourie, M. J. Dyer, K. Moloni, T. F. Kelly, and R. S. Ruoff, "Strength and breaking mechanism of multiwalled carbon nanotubes under tensile load," Science, Vol. 287, No. 5453, pp. $637-$ 640, 2000.

[47] A. Krishnan, E. Dujardin, T. Ebbesen, P. Yianilos, and M. Treacy, "Young's modulus of single-walled nanotubes," Physical Review B, Vol. 58, No. 20, p. 14013, 1998.

[48] M. Loos, "Chapter 3 - Allotropes of Carbon and Carbon Nanotubes," in Carbon Nanotube Reinforced Composites, M. Loos, Ed., ed Oxford: William Andrew Publishing, 2015, pp. 73-101.

[49] X. Chen, C. Chen, H. Xiao, F. Cheng, G. Zhang, and G. Yi, "Corrosion behavior of carbon nanotubes-Ni composite coating," Surface and Coatings Technology, Vol. 191, No. 2, pp. 351-356, 2005.

[50] B. Praveen, T. Venkatesha, Y. A. Naik, and K. Prashantha, "Corrosion studies of carbon nanotubes-Zn composite coating," Surface and Coatings Technology, Vol. 201, No. 12, pp. 5836-5842, 2007.

[51] A. K. Keshri, V. Singh, J. Huang, S. Seal, W. Choi, and A. Agarwal, "Intermediate temperature tribological behavior of carbon nanotube reinforced plasma sprayed aluminum oxide coating," Surface and Coatings Technology, Vol. 204, No. 11, pp. 1847-1855, 2010.

[52] I. Ahmad, M. Unwin, H. Cao, H. Chen, H. Zhao, A. Kennedy, et al., "Multi-walled carbon nanotubes reinforced $\mathrm{Al} 2 \mathrm{O} 3$ nanocomposites: mechanical properties and interfacial investigations," Composites Science and Technology, Vol. 70, No. 8, pp. 1199-1206, 2010.

[53] K. Balani, S. P. Harimkar, A. Keshri, Y. Chen, N. B. Dahotre, and A Agarwal, "Multiscale wear of plasma-sprayed carbon-nanotube- 
reinforced aluminum oxide nanocomposite coating," Acta Materialia, Vol. 56, No. 20, pp. 5984-5994, 2008.

[54] C. F. Gutierrez-Gonzalez, A. Smirnov, A. Centeno, A. Fernández, B. Alonso, V. G. Rocha, et al., "Wear behavior of graphene/alumina composite," Ceramics International, Vol. 41, No. 6, pp. 7434-7438, $7 / / 2015$.

[55] M. O. Bodunrin, K. K. Alaneme, and L. H. Chown, "Aluminium matrix hybrid composites: a review of reinforcement philosophies; mechanical, corrosion and tribological characteristics," Journal of Materials Research and Technology, Vol. 4, No. 4, pp. 434-445, 2015.

[56] D. Kaewsai, A. Watcharapasorn, P. Singjai, S. Wirojanupatump, P. Niranatlumpong, and S. Jiansirisomboon, "Thermal sprayed stainless steel/carbon nanotube composite coatings," Surface and Coatings Technology, Vol. 205, No. 7, pp. 2104-2112, 2010.

[57] S. Singhal, R. Pasricha, M. Jangra, R. Chahal, S. Teotia, and R. Mathur, "Carbon nanotubes: amino functionalization and its application in the fabrication of Al-matrix composites," Powder Technology, Vol. 215, pp. 254-263, 2012.

[58] D.-S. Lim, D.-H. You, H.-J. Choi, S.-H. Lim, and H. Jang, "Effect of CNT distribution on tribological behavior of alumina-CNT composites," Wear, Vol. 259, No. 1, pp. 539-544, 2005.

[59] C. Kwok, P. Wong, F. Cheng, and H. Man, "Characterization and corrosion behavior of hydroxyapatite coatings on Ti6Al4V fabricated by electrophoretic deposition," Applied Surface Science, Vol. 255, No. 13, pp. 6736-6744, 2009.

[60] M. Mazaheri, D. Mari, Z. R. Hesabi, R. Schaller, and G. Fantozzi, "Multi-walled carbon nanotube/nanostructured zirconia composites: Outstanding mechanical properties in a wide range of temperature," Composites Science and Technology, Vol. 71, No. 7, pp. 939-945, 2011.

[61] A. K. Keshri, J. Huang, V. Singh, W. Choi, S. Seal, and A. Agarwal, "Synthesis of aluminum oxide coating with carbon nanotube reinforcement produced by chemical vapor deposition for improved fracture and wear resistance," Carbon, Vol. 48, No. 2, pp. 431-442, 2010.

[62] H. Li, Y. Xie, K. Li, L. Huang, S. Huang, B. Zhao, et al., "Microstructure and wear behavior of graphene nanosheets-reinforced zirconia coating," Ceramics International, Vol. 40, No. 8, Part B, pp. $12821-12829,9 / / 2014$

[63] G. Han, Z. Wang, K. Liu, S. Li, X. Du, and W. Du, "Synthesis of CNT-reinforced AZ31 magnesium alloy composites with uniformly distributed CNTs," Materials Science and Engineering: A, Vol. 628, No. 0, pp. 350-357, 3/25/ 2015.

[64] S. R. Bakshi, V. Singh, K. Balani, D. G. McCartney, S. Seal, and A. Agarwal, "Carbon nanotube reinforced aluminum composite coating via cold spraying," Surface and Coatings Technology, Vol. 202, No. 21, pp. 5162-5169, 2008. 